\title{
ANÁLISE DAS MANIFESTAÇÕES PATOLÓGICAS EM SISTEMAS HÍBRIDOS: MADEIRA X STEEL FRAME
}

\author{
SOUTO COSTA COELHO DA SILVA, CATHERINE \\ Mestre em Estruturas \\ UNICAMP \\ São Paulo; Brasil \\ cathe.catita@gmail.com
}

\author{
CRISTINA DOS SANTOS FERREIRA, GISLEIVA \\ Engenheira Civil \\ UNICAMP \\ São Paulo; Brasil \\ gisleiva@ft.unicamp.br
}

\author{
LEANDRO SILVA, THALITA \\ Engenheira Civil \\ UNICAMP \\ São Paulo; Brasil \\ eng.thalitaleandro@gmail.com
}

\author{
MARIA GUIDA SERRA, VIVIAN \\ Engenheira Civil \\ FACENS \\ São Paulo; Brasil \\ vivianmguida@hotmail.com
}

\author{
BETANIA SCALI, SILVIA \\ Arquiteta e Urbanista \\ UNICAMP \\ São Paulo; Brasil \\ silvia@scali.com.br
}

\author{
TADEU MASCIA, NILSON \\ Engenheiro Civil \\ UNICAMP \\ São Paulo; Brasil \\ nilson@fec.unicamp.br
}

\author{
DROZDOWSKI PRIOSTA, THIAGO \\ Engenheiro Civil \\ UNIANCHIETA \\ São Paulo; Brasil \\ thiago.priosta@anchieta.br
}

\section{RESUMO}

Novos sistemas construtivos têm sido explorados, focando na sustentabilidade de novas construções, tanto em aspectos ambientais, sociais e econômicos. O sistema híbrido, que mescla diferentes materiais na construção de edificações tanto residenciais quanto comerciais, ganhou espaço pois otimiza recursos, gera menos resíduos e reduz o tempo dos processos. A junção desses dois materiais de características distintas acaba acarretando diferentes tipos de trabalhabilidade, o que torna necessário a identificação das manifestações patológicas e dos fatores passíveis de manutenção corretiva. Este artigo abordará a análise das manifestações patológicas e relatadas em 2 residências situadas no interior de São Paulo identificando assim as vantagens e desvantagens do sistema híbrido.

Palavras-Chave: Manifestações Patológicas, Madeira, Steel Frame, Dry-wall, Sistema Híbrido.

\begin{abstract}
New building systems have been explored, focusing on the sustainability of new buildings, both in environmental, social and economic aspects. The hybrid system, which mixes different materials in the construction of both residential and commercial buildings gained space because it optimizes resources, generates less waste and reduces process time. In this paper will be presented the hybrid system between wood and steel frame. The combination of these two materials with different characteristics ends up causing different types of workability, which makes it necessary to identify the correctable maintenance factors and the pathological manifestations. This paper will address the analysis of known pathological manifestations reported in 2 residences located in the countryside of São Paulo state thus identifying the advantages and disadvantages of this hybrid system.

Keywords: Pathological Manifestations, Wood, Steel Frame, Dry-wall, Hybrid System
\end{abstract}




\section{INTRODUÇÃO}

No Brasil o uso do Steel Frame teve início em 1998 na construção de residências com novas tendências tecnológicas no sistema construtivo, resultando em grandes vantagens para o construtor e o consumidor. A metodologia aplicada traz componentes industrializados conseguindo promover o controle do produto final, de forma segura e sem riscos de desvios nos procedimentos de materiais e serviços durante a etapa da construção.

Por ser um método de construção civil prático, de baixo custo, rápido, com grande flexibilidade, e preservação ambiental, este se tornou tendência tendo em vista as necessidades apresentadas por uma sociedade em desenvolvimento.

Assim, uma nova demanda começou a surgir no mercado brasileiro, mesclando o sistema construtivo pilar-viga de madeira com vedações de materiais diversos e esse novo sistema começou a gerar questionamentos em torno de qual a forma mais adequada de utilização, quais técnicas aplicar na ligação da interface destes materiais, quais os comportamentos desses materiais em conjunto, suas vantagens e desvantagens, entre outros.

Também ocorre a inserção de madeira laminada colada (MLC) e madeira laminada cruzada (CLT - Cross Laminated Timber) juntamente com o steel frame, onde neste caso, a velocidade de execução do referido sistema construtivo é o fator preponderante quando da sua escolha. Aliado a isso, o baixo peso próprio e a alta resistência dos compontes, o tornam um vantajoso modelo construtivo nos dias atuais. Com relação a este artigo, o mesmo estará focado apenas nas madeiras maciças roliças e não nos modelos híbridos steel frame x MLC ou CLT.

Mesmo para os sistemas híbridos steel frame $\mathrm{x}$ madeiras, apesar das vantagens observadas, alguns efeitos danosos podem ser verificados. A exemplo disto, a durabilidade das edificações, bem como sua capacidade de resistir à intempéries podem ser diminuídas, considerando a interação da estrutura não só com o ambiente a que está inserido, mas também com as condições de uso, operação e manutenção associado ao uso de materiais com trabalhabilidades e comportamentos distintos.

As manifestações identificadas neste trabalho são intrínsecas à tipologia de construção híbrida em virtude da trabalhabilidade diferente dos materiais. A origem de maior ou menor quantidade destas manifestações patológicas podem ter origem nas falhas decorrentes da concepção ainda na fase de projeto, na negligência durante a execução de medidas preventivas que minimizem tais ocorrências ou na ausência de manutenções preventivas por parte do usuário.

Diante disso, o presente trabalho procurou avaliar com base em conteúdo empírico relativo às construções híbridas, apresentando projeto, dados, figuras (fotos com conteúdo ilustrativo de obras) e análises de obras com objetivo de demonstrar as vantagens e desvantagens do sitema híbrido madeira $\mathrm{x}$ steel frame, com base nas manifestações patológicas identificadas, determinando ações para minimizar as incidências, prolongando assim a vida útil da construção e então fornecer informações técnicas aos profissionais que atuam na área de especificação de materiais, visando, deste modo, otimizar, difundir técnicas e/ou elaborar novas técnicas construtivas, bem como contribuir para a sustentabilidade no setor da construção a partir do uso da madeira como material construtivo.

\section{STEEL FRAME}

O Steel frame teve seu início historicamente ligado ao modelo de construção em habitações de madeira contruídas principalmente pelos colonizadores em território americano mais precisamente no início do século XIX.

Este sistema construtivo também conhecido como construção LSF (Light Steel Framing) é reconhecido internacionalmente por utilizar o aço galvanizado como principal elemento estrutural, gerando edificações de baixo peso próprio e entre outras vantagens destaca-se também a velocidade de construção. Santos (2019) aborda que dadas as vantagens econômicas, funcionais e ambientais, O LSF está ganhando participação de mercado, principalmente para edifícios residenciais baixos, principalmente em relação à estrutura tradicional de concreto e à construção de paredes de alvenaria.

Segundo Castro e Freitas (2006) o modelo teve sua dissiminação para diversos terrítorios como por exemplo, no Japão, onde após a segunda guerra mundial houve grande necessidade de construção de aproximadamente quatro milhões de casas em pequeno espaço de tempo. 
No Brasil de acordo com Penna (2009), somente após 1998 essa tecnologia passou a ser utilizada, sendo os primeiros projetos atribuídos à edificações de médio e alto padrão. Atualmente o Steel Frame vem sendo empregado em grande escala para a construção de conjuntos habitacionais em virtude de sua industrialização, gerando produtividade e racionalização dos processos construtívos, tornando o mercado mais competitivo para as empresas e seus colaboradores.

\section{SISTEMA HÍBRIDO}

As construções em sistemas híbridos (interação entre dois materiais de diferentes naturezas) procuram aliar os fatores positivos de cada metodologia/material. O fato de não precisar de grandes manutenções e reparos faz com que exista uma baixa geração de resíduos agressivos ao meio ambiente, consequentemente tem-se baixo custo e a possibilidade de utilizar novos materiais ecologicamente corretos, dando assim uma pequena contribuição para o processo de sustentabilidade na Construção Civil. A preocupação em construir edifícios que apresentem alto potencial de durabilidade é alcançada através do avanço na tecnologia e na ciência dos materiais, além de se buscar especiais cuidados à manutenção e na utilização dos edifícios.

A evolução da construção civil com a busca pela racionalização acaba trazendo novas tipologias para as edificações que permitem uma redução global nos custos. Dentro desta linha de racionalização, as vedações podem ser realizadas em fechamentos diversos, sendo denominadas Sistemas Híbridos (devido a interação entre diferentes materiais). Esse trabalho está focado na análise das manifestações patológicas em sistemas utilizando o fechamento externo em placas cimentícias e internos em placas de gesso acartonado (dry-wall).

\subsection{Fechamentos externos em placas cimentícias}

Placas cimentícias são produzidas a partir de miolo de madeira laminada ou sarrafeada entre placas também em madeira que externamente em ambas as faces possuem ainda placas cimentícias formadas por CRFS (Cimento Reforçado por Fibra Sintética). Estes compostos são prensados sob alta temperatura garantindo uniformidade e boa resistência à peça. Essas placas podem ser fornecidas já com acabamento final ou esse acabamento ser realizado em obra a depender do tipo de textura adotada.

A fixação dessas placas é realizada por meio de quadros modulares (montantes e guias) do próprio Steel Frame, gerando boas condições de travamentos dos paineis mesmo quando utilizado na vertical. Este sistema de fixação e montagem pode ainda receber reforços em regiões onde se concentram tensões, como por exemplo nos cantos e nas ligações das placas.

\subsection{Fechamentos internos em gesso acartonado (drywall)}

Segundo Ciocchi (2003), a placa de gesso acartonado foi inventada no final do século XIX e passou a ser empregada como elemento construtivo por reunir a qualidade da madeira (facilidade de trabalho) e da pedra (isolamento térmico, acústico e resistência ao fogo). É composta de um miolo de gesso e aditivos envoltos por cartão especial e fabricada a partir da gipsita natural. Essas placas de gesso acartonado são fixadas a uma estrutura metálica, podendo ser aplicadas como paredes e forros. Ainda, possui como aplicação menos usual a fixação colada sobre paredes de alvenaria.

Sistemas construtivos leves, como o Light Steel Frame, abordado neste estudo, utilizam o gesso acartonado rotineiramente como revestimento interno em suas unidades. Isso ocorre devido ao fato de que sua durabilidade é sensivelmente diminuída quando expostas às intempéries de modo contínuo, apesar de existirem placas com tratamento contra a umidade. Outra característica importante é que estas placas em gesso acartonada são relativamente leves se comparadas a outros materiais utilizados como fechamento, como por exemplo, as próprias alvenarias em blocos. 


\section{MANIFESTAÇÕES PATOLÓGICAS}

Para Barros e Sabbatini (2001) uma manifestação patológica ocorre em uma edificação quando esta, em um determinado período de sua vida útil, não apresenta o desempenho previsto. De acordo com a NBR 15575-1 (ABNT, 2013), o conceito de desempenho implica quais as condições devem ser satisfeitas pela edificação e respectivas instalações, tanto em relação aos requisitos técnicos como aos do usuário, quando submetida às condições normais de uso. Portanto, a norma citada pode ser adotada como parte dos procedimentos de avaliação dos sistemas construtivos, o que pode minimizar as possíveis não conformidades e, consequentemente, melhorar a qualidade destas construções, visando a segurança, sustentabilidade e habitabilidade (ANTUNES, 2010; SILVA, 2009).

As manifestações patológicas que ocorrem ao longo da vida útil do edifício, tem origem principalmente nas fases de projeto e/ou execução. A manifestação patológica na fase de projeto ocorre pela inexistência de um projeto específico ou por erros em sua concepção. Já em relação à fase de execução, as manifestações ocorrem devido à má execução, que pode ser pela mão de obra não especializada ou pela falta de informação e domínio das técnicas de execução (GROFF, 2011).

A causa das manifestações patológicas, de acordo com Helene (1993, apud Silva (2007), está relacionada a vários fenômenos que influenciam no surgimento das anomalias, merecendo destaque as cargas excessivas, a variação de umidade, as variações térmicas, os agentes biológicos, a incompatibilidade de materiais, entre outros.

Os problemas patológicos são evolutivos e tendem a se agravar com o passar do tempo, podendo até gerar novas manifestações em decorrência das primeiras, de modo que se pode afirmar que as correções serão mais duráveis, mais efetivas, mais fáceis e mais baratas se forem executadas, quanto antes se apresentarem os problemas, como expressa a lei de Sitter. (SILVA, 2007).

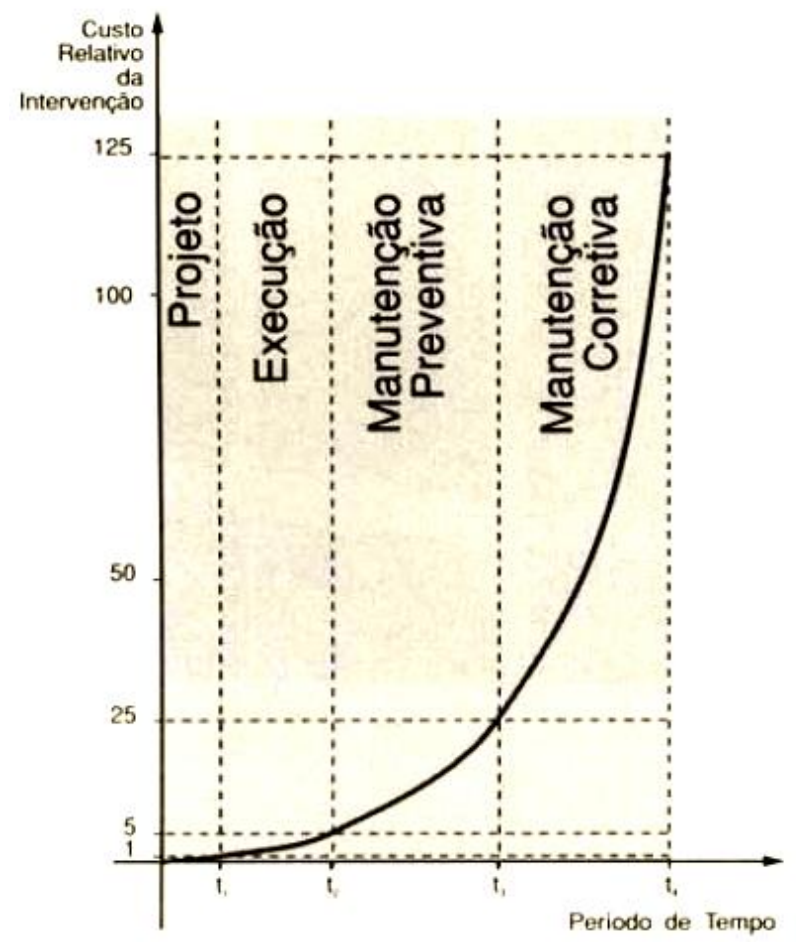

Figura 1: Lei da evolução dos custos (Adaptado de SOUZA e RIPPER, 1998)

Este conceito da Lei de Sitter ou Lei de Evolução dos Custos visa demonstrar que os custos de intervenção crescem em função do tempo e segundo uma progressão geométrica de razão cinco. 


\subsection{Manifestações Patológicas em Madeira}

Na madeira, as principais manifestações patológicas que ocorrem são: alterações nas características físicas e químicas, perda de resistência devido a degradação do material, degradação superficial por apodrecimento, degradação por agentes atmosféricos , empenamento por secagem não controlada, dilatação ou retração devido as condições ambientais, deformações e vibrações excessivas, falhas nas ligações e/ou problemas nos apoios. As causas principais estão ligadas a ventilação insuficiente, falta de proteção superficial, erro na concepção, falta de limpeza e manutenção, agentes de degradação bióticos (fungos, bactérias, insetos xilófagos e xilófagos marinhos).

\subsection{Manifestações Patológicas em Steel Frame}

No sistema ligh steel frame também ocorrem manifestações patológicas, sendo as mais frequentes: fissuras, falhas nas juntas entre chapas, vedações não aprumadas e umidade.

As fissuras ocorrem quando as vedações sofrem solicitação maior do que as dimensionadas. A resistência desse tipo de vedação aos esforços depende do material utilizados nas placas de fechamento e no sistema de fixação. Gaião, Brito e Silvestre (2011) citam que as fissuram são uma das manifestações patológicas mais encontradas nas placas de gesso do sistema cosntrutivo steel frame. Esta afirmação é corroborada por Campos (2010), que realizou uma avaliação de pós ocupação onde os usuários relataram a ocorrência de fissuras nas placas de fechamento da edificação onde os fechamentos externos eram em placas cimentícias e os internos em placas de gesso acartonado.

Gaião, Brito e Silvestre (2011) observam ainda falhas nas juntas entre as placas, caracterizadas pelo destacamento da fita das juntas, geralmente ocasionados por erros na etapa de montagem dos painéis. Estas manifestações proporcionam declínio de desempenho dos sistemas de vedações podendo ocasionar entrada de umidade, perda de desempenho e prejuízo visual do ponto de vista estético/arquitetônico.

\subsection{Manifestações Patológicas do Sistema Híbrido: Madeira x Steel Frame}

No sistema híbrido utilizando Madeira e Steel frame é comum haver o descolamento entre a estrutura de madeira e as placas de fechamento, fissuras horizontais entre as placas, destacamento da fita entre as juntas que podem evidenciar fissuras e então afetar o revestimento e fissuras diagonais que ocorrem normalmente em residências de dois ou mais pavimentos.

\section{ESTUDO DE CASO}

Além da fundamentação teórica apresentada nos capítulos anteriores, foi realizada uma análise de duas residências na cidade de Itatiba, interior do Estado de São Paulo, sendo as duas com dois pavimentos. Essas obras foram executadas entre os anos de 2012 e 2015 em sistema híbrido madeira e steel frame conforme se delineia na Tabela 1:

Tabela 1 - Residências analisadas

\begin{tabular}{c|c|c|c|c|c}
\hline Caso & Residência & Local & Idade da Construção & Tipologia & Área $\left(\mathrm{m}^{2}\right)$ \\
\hline A & S \& L & Itatiba - SP & 7 anos & 2 Pavimentos & 250 \\
\hline B & L \& V & Itatiba - SP & 4 anos & 2 Pavimentos & 130 \\
\hline
\end{tabular}

Ambas as edificações tratam de residência unifamiliar construídas em sistema estrutural de madeira tipo pilar/viga, com uso de Eucaliptus Citriodora roliço tratado em autoclave.

As análises de cada uma das residências, com ênfase nas manifestações encontradas em cada uma delas e método sugerido para reabilitação. A metodologia de reparo indicada é a que apresentou, nas referidas situações, um melhor desempenho frente às necessidades e causas geradoras das manifestações patológicas.

Muitas das manifestações observadas possuem origem nas movimentações dos materiais, que por terem propriedades fisicas e mecânicas diferentes (madeira x steel frame com fechamento em placas cimentícias e/ou gesso acartonado), acabam se movimentando também de modo diferente. Em alguns casos ainda, ocorrem também as vedações em alvenaria, o que acarreta em um número de manifestações patológicas maiores em virtude da interação dos materiais com diversos tipos de propriedades. 


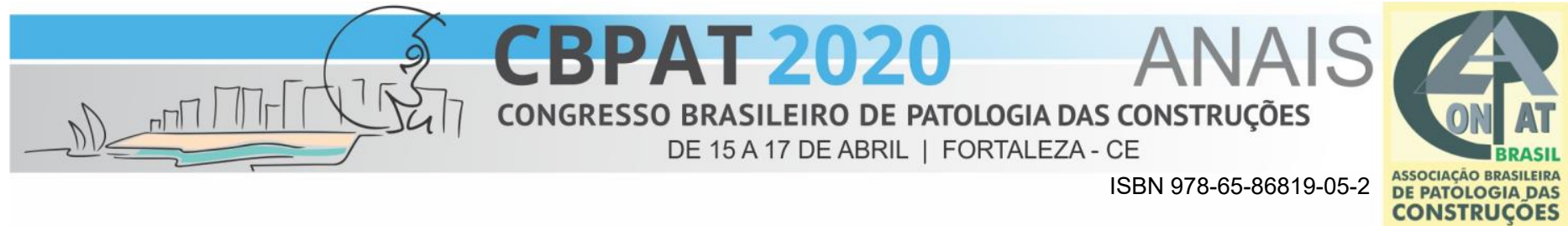

\subsection{Caso A}

Nas Figuras 2 à 5 são observadas algumas etapas da construção da residência em análise, podendo verificar o método de construção em sistema híbrido. Com utilização de madeira maciça roliça, Steel Frame e vedações em alvenaria e placas cimentícias.

Já nas Figuras 6 à 9, observam-se manifestações patológicas típicas das movimentações dos materiais constituintes da estrutura e do fechamento da edificação.

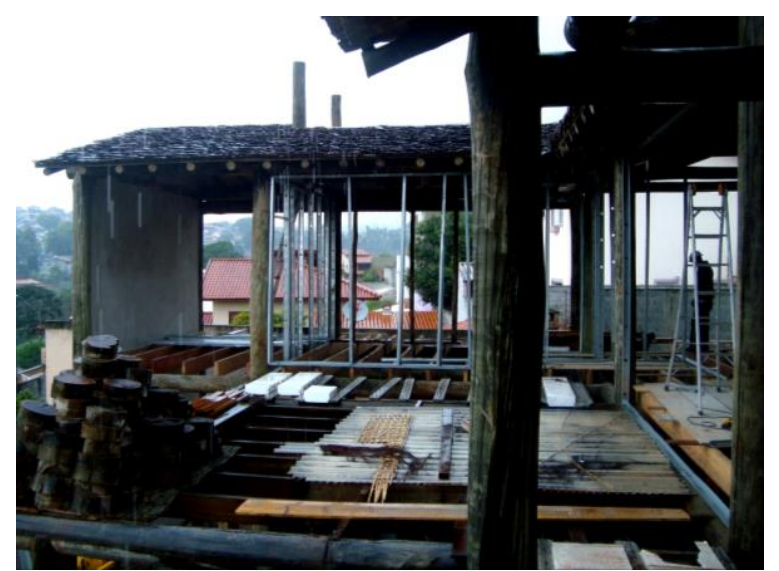

Figura 2: Estrutura pilar x viga em madeira e Steel Frame (Fonte: Autores)

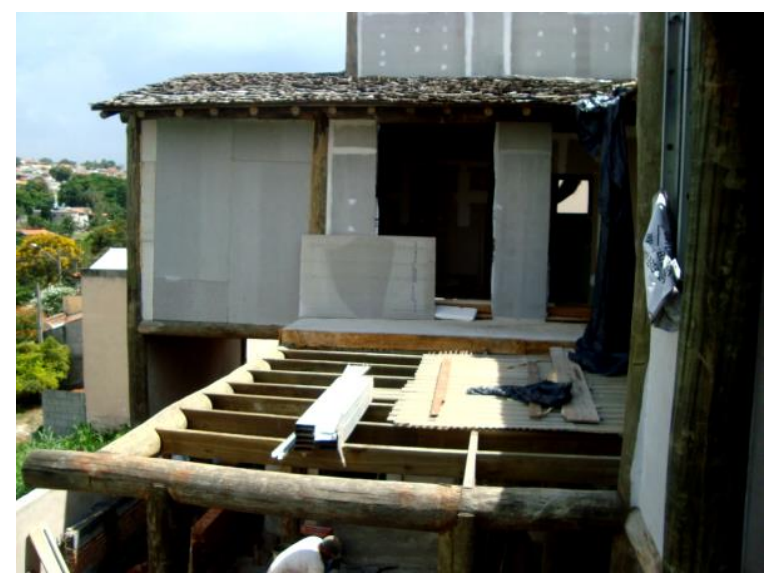

Figura 4: Estrutura pilar x viga em madeira e Steel Frame (Fonte: Autores)

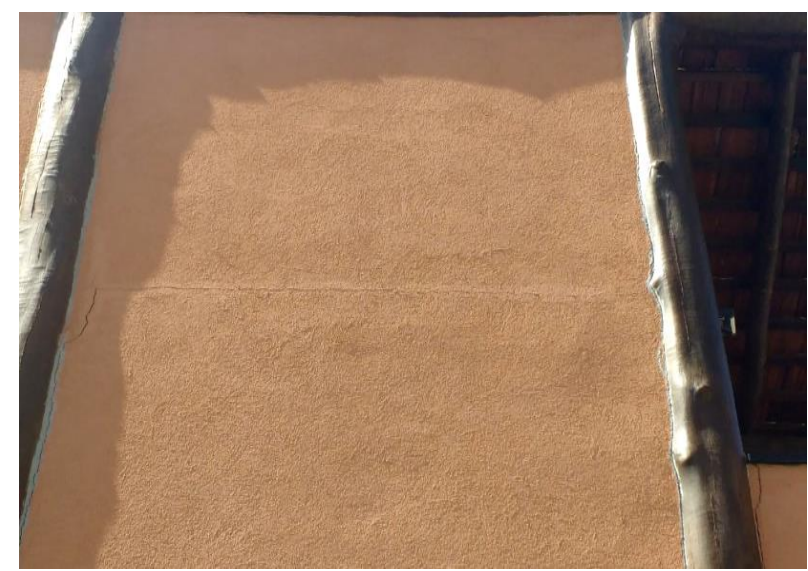

Figura 6: Fissura localizada na emenda de placas (Fonte: Autores)

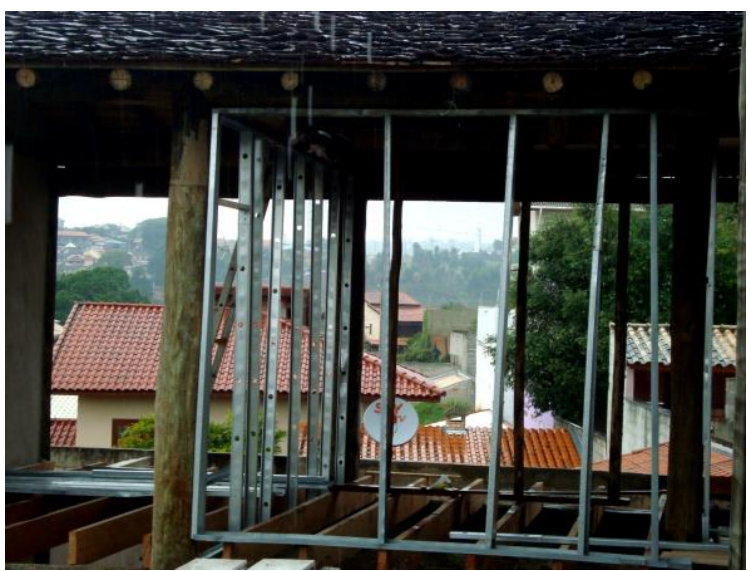

Figura 3: Quadros modulares do Steel Frame (Fonte: Autores)

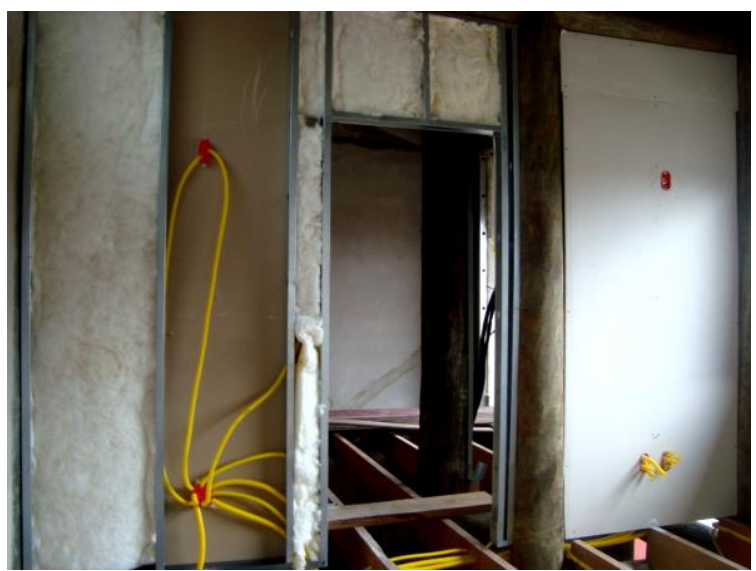

Figura 5: Placas de fechamento do Steel Frame (Fonte: Autores)

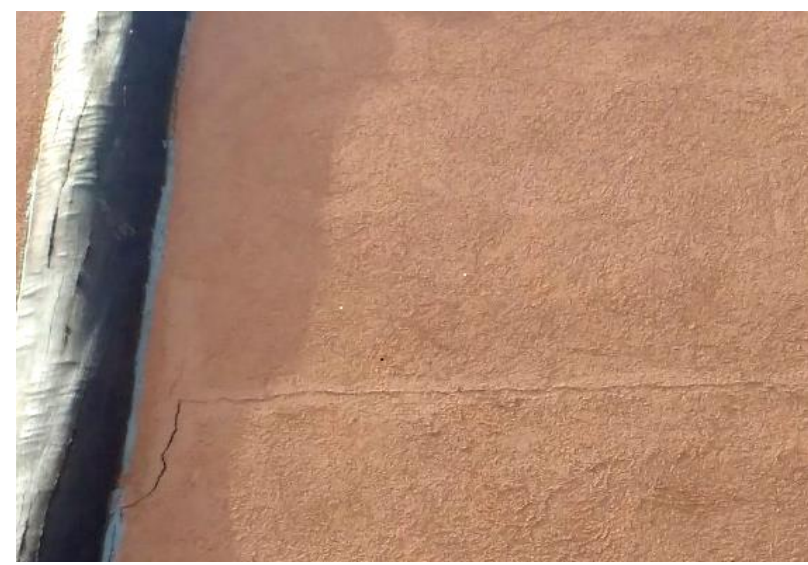

Figura 7: Fissura localizada na emenda de placas (Fonte: Autores) 

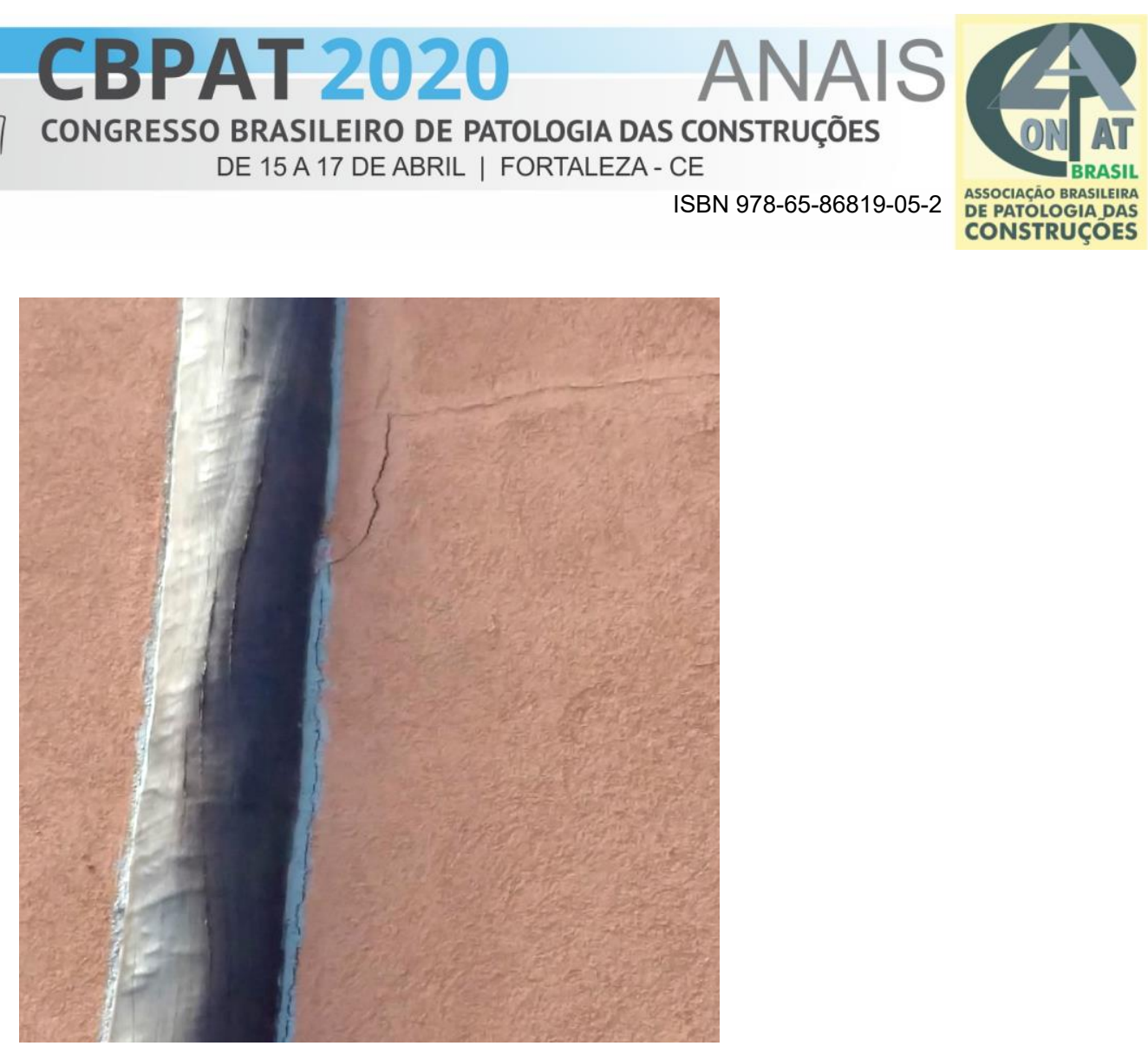

Figura 8: Fissura localizada na encontro entre placas e estrutura de madeira (Fonte: Autores)

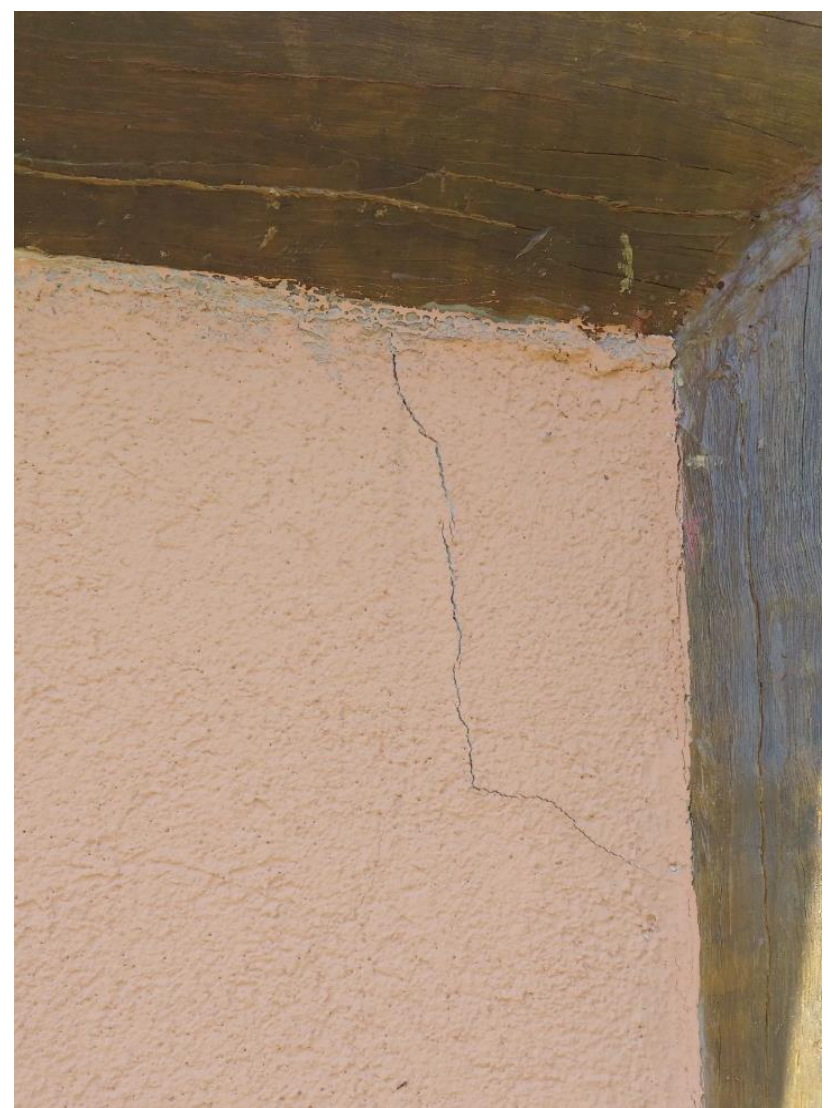

Figura 9: Fissura inclinada no encontro com da placa de fechamento com a estrutura de madeira (Fonte: Autores)

Ainda que se tratassem do mesmo material (mesmo coeficiente de dilatação térmica), peças com volumes e dimensões muito diferentes também podem apresentar movimentações diferentes e por este motivo, juntas entre os elementos são recomendados, para permitir que estes possam se deformar e/ou deslocar livremente. 
No caso das referidas Figuras 6 à 9, exatamente por se tratarem de elementos com origens e características distintas, estes possuem coeficientes de dilatação térmica também distintas, maximizando o surgimento das patologias ora visualizadas. O emprego de materiais diferentes nas edificações deve levar em consideração a interação entre estes, de modo a mitigar os efeitos deletérios que podem surgir nas mesmas. Para as situações apresentadas, observa-se que por se tratarem de manifestações patológicas em elementos sujeitos a insolação frequente e portanto, alto gradiente térmico, os materiais (madeira e elementos de fechamento do steel frame) se deformam bastante e na ausência de espaço suficiente para deformação, tensões localizadas geram as fissuras, conforme a visualizada na Figura 9.

Aliado a esta condição, ainda pode-se destacar que a madeira é um material que está sob influência constante da umidade do ambiente a seu redor, podendo também sofrer, assim como o material de fechamento nela encostado, de movimentações (dilatação ou retração) por umidade.

Para a Figura 6, observa-se uma fissura horizontal com mudança de direção próxima a região da estrutura. Nesta condição, a emenda das placas de fechamento do steel frame é bem visualizada, pois se trata de uma região mais frágil (emenda) que se não bem tratada durante a fase executiva, pode apresentar fissuras quando das movimentações térmicas e por umidade já citadas. Também cabe destacas que pelo simples fato de ser uma emenda, quando de fato má executada, poucas movimentações já são capazes de gerar estas patologias visualizadas.

O tratamento das manifestações patológicas demonstradas nas Figuras 7 à 9 é realizado ou pela execução da ligação entre os elementos (madeira e placa de fechamento) com uma certa folga que posteriormente é preenchido com material elastomérico capaz de absorver as movimentações supracitadas ou então, posterior a execução, pela abertura manual desta região e então complemento também com material capaz de absorver as deformações e movimentações. Importante observar que estes materiais possuem a necessidade de manutenção, isto é, a troca destes materiais nas juntas deve ser realizada de modo regular, permitindo que o conjunto continue a exercer comportamento satisfatório, não apenas na absorção das movimentações como também no isolamento entre um lado e outro da parede.

\subsection{Caso B}

Nas Figuras 10 à 12 são observadas algumas etapas da construção da residência em análise, podendo verificar o método de construção em sistema híbrido semelhante ao do Caso A. Com utilização de madeira, Steel Frame e vedações em placas cimentícias.

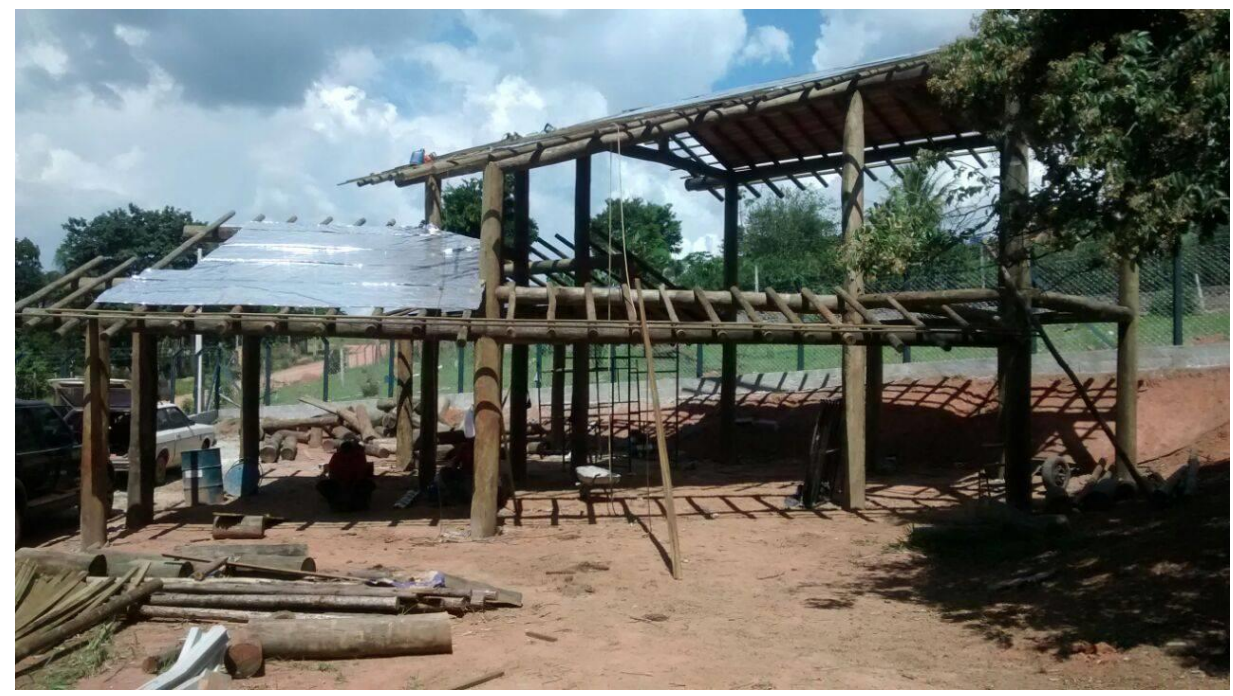

Figura 10: Estrutura pilar $\mathrm{x}$ viga em madeira

(Fonte: Autores) 

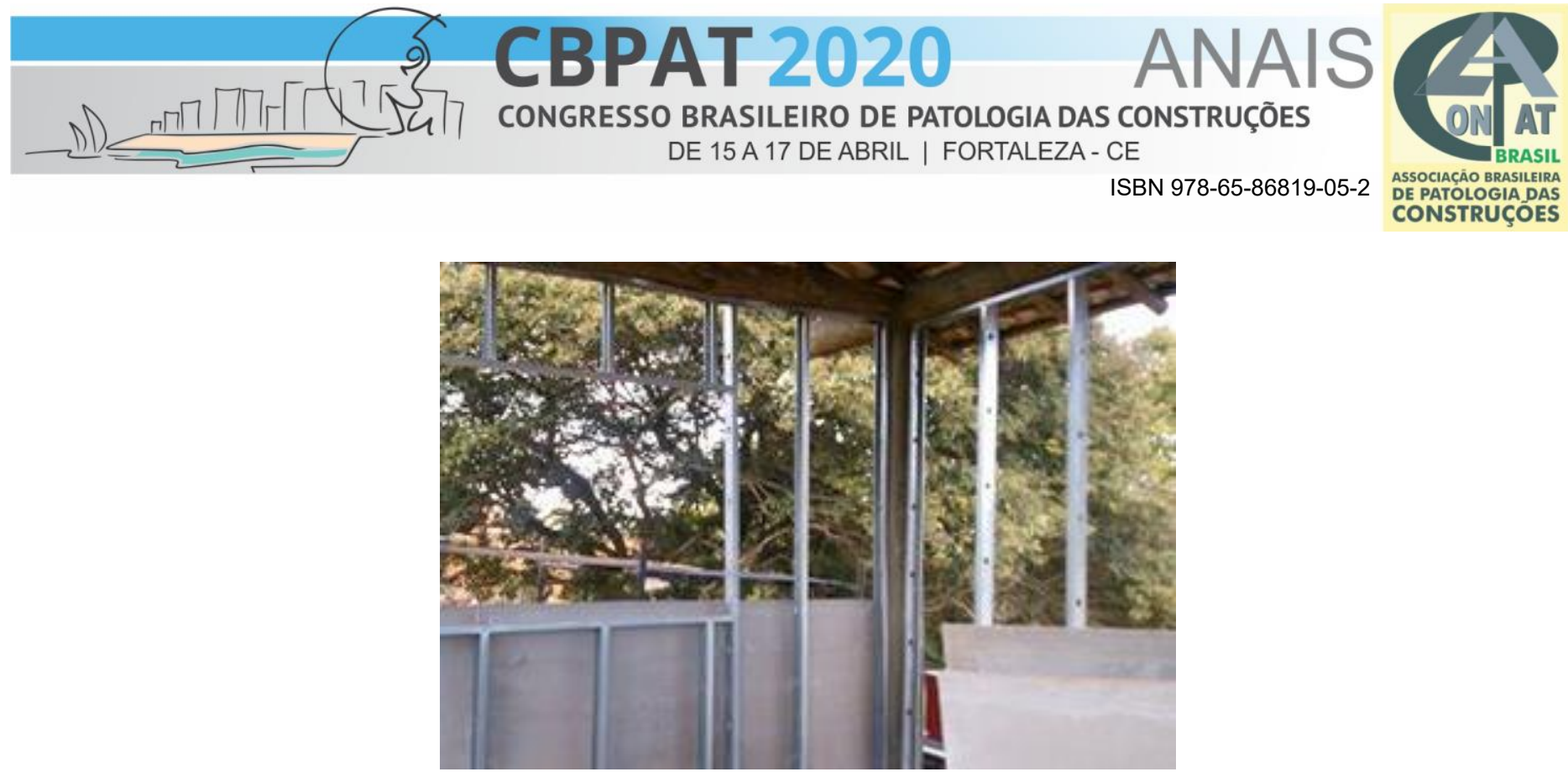

Figura 11: Perfis e quadros utilizados como montantes para colocação das placas de fechamento (Fonte: Autores)

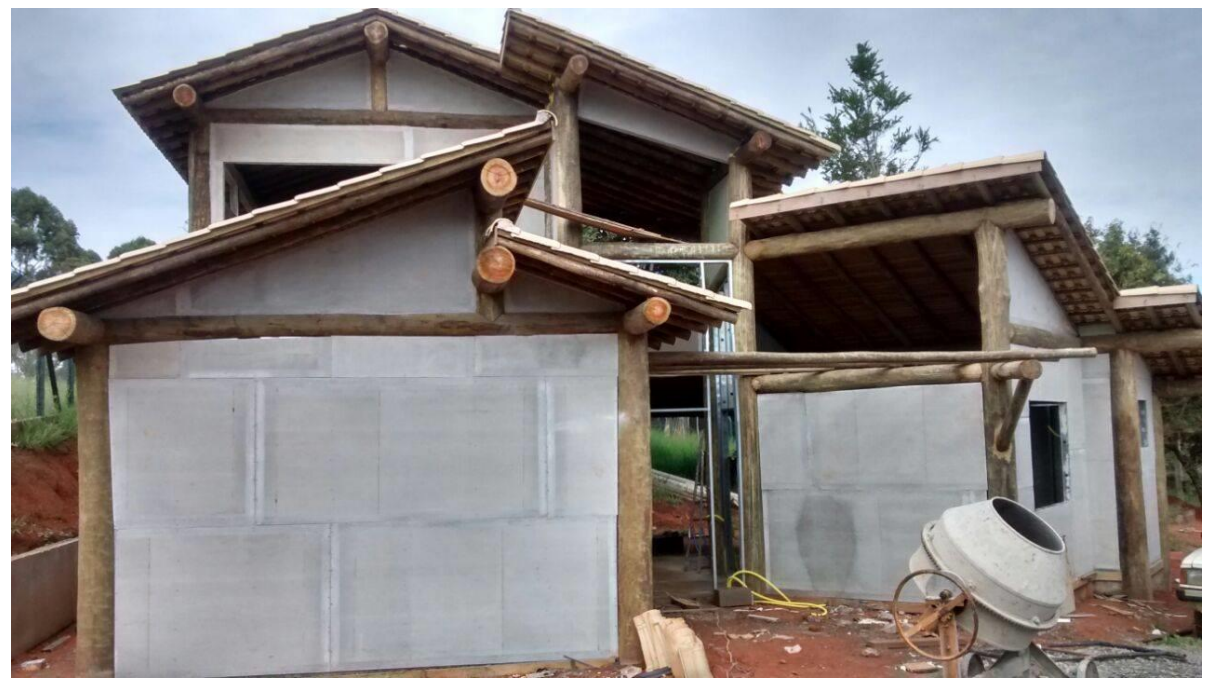

Figura 12: Estrutura pilar x viga em madeira com Steel Frame de fechamento

(Fonte: Autores)

Nas Figuras 13 a 17 a seguir, pode-se observar o aparecimento de manifestações patológicas na residência em análise. A manifestação apresentada nessas Figuras é o descolamento entre a estrutura de madeira e as placas de fechamento.
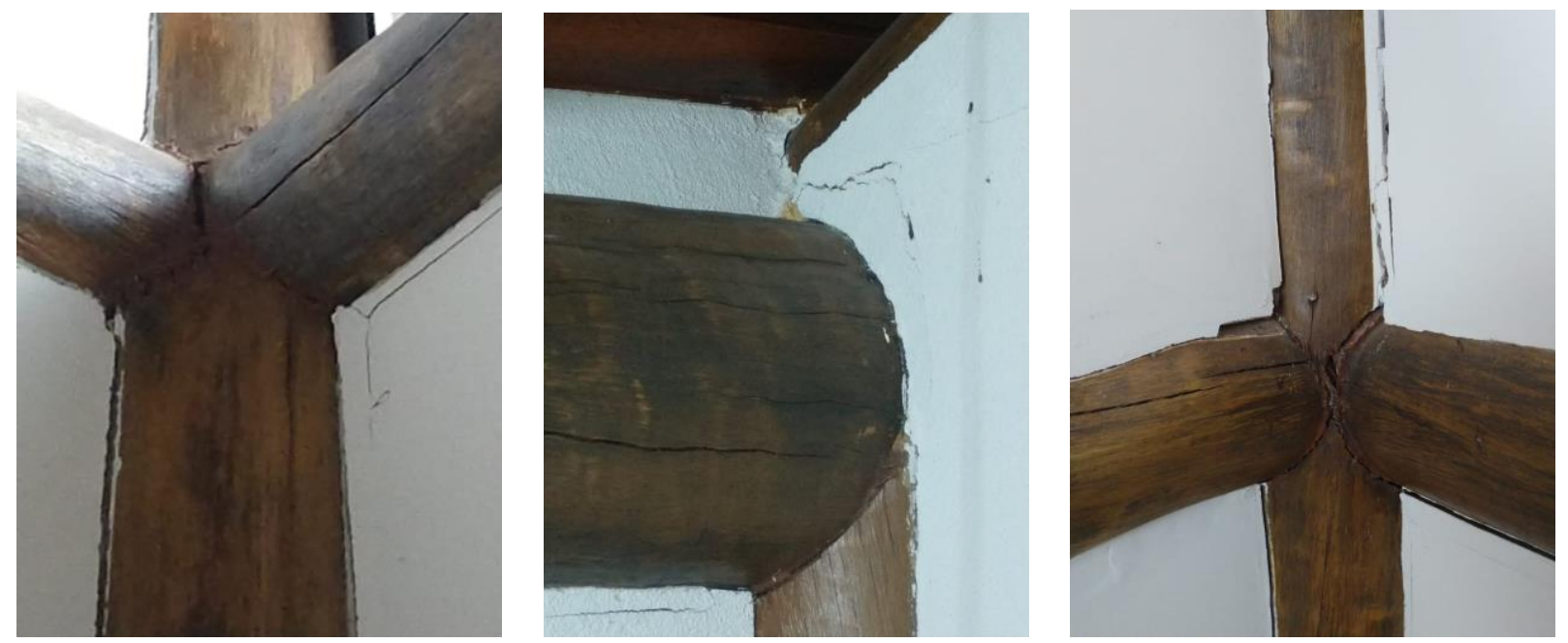

Figuras 13, 14 e 15: Descolamento da placa de fechamento da estrutura causando fissuras.

(Fonte: Autores) 

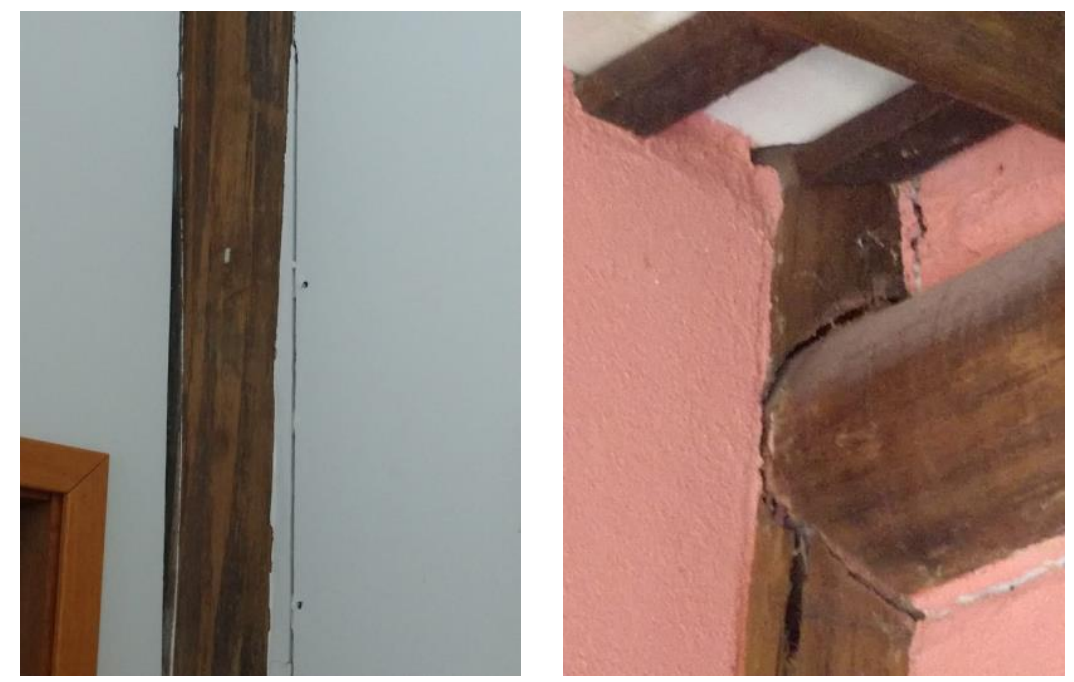

Figuras 16 e 17: Descolamento da placa de fechamento da estrutura causando fissuras. (Fonte: Autores)

Essa manifestação como observado podem ocorrer interna e externamente na placa de fechamento e ocorre devido a diferença de dilatação dos materiais, principalmente na interface das mesmas. A madeira expande ou retrai de acordo com as variações de umidade no ambiente, ocasionando maior incidência de manifestações patológicas nos pontos em que os pilares estão faceando as fachadas, refletindo nas paredes internas conforme as Figuras abaixo.

A forma de mitigar e/ou reparar esse tipo de manifestação é primeiramente fazer a ligação das placas cimentícias de forma adequada utilizando fitas próprias para tratamento de juntas e aplicação de PU selante flexível que apresenta ótimo desempenho nas interfaces pilar-perfil metálico-placas.

Nas Figuras 18 à 20 pode-se observar o aparecimento da manifestação de fissuras horizontais e/ou verticais entre as placas que acabam acarretando fissuras no revestimento que foi aplicado nessa região.
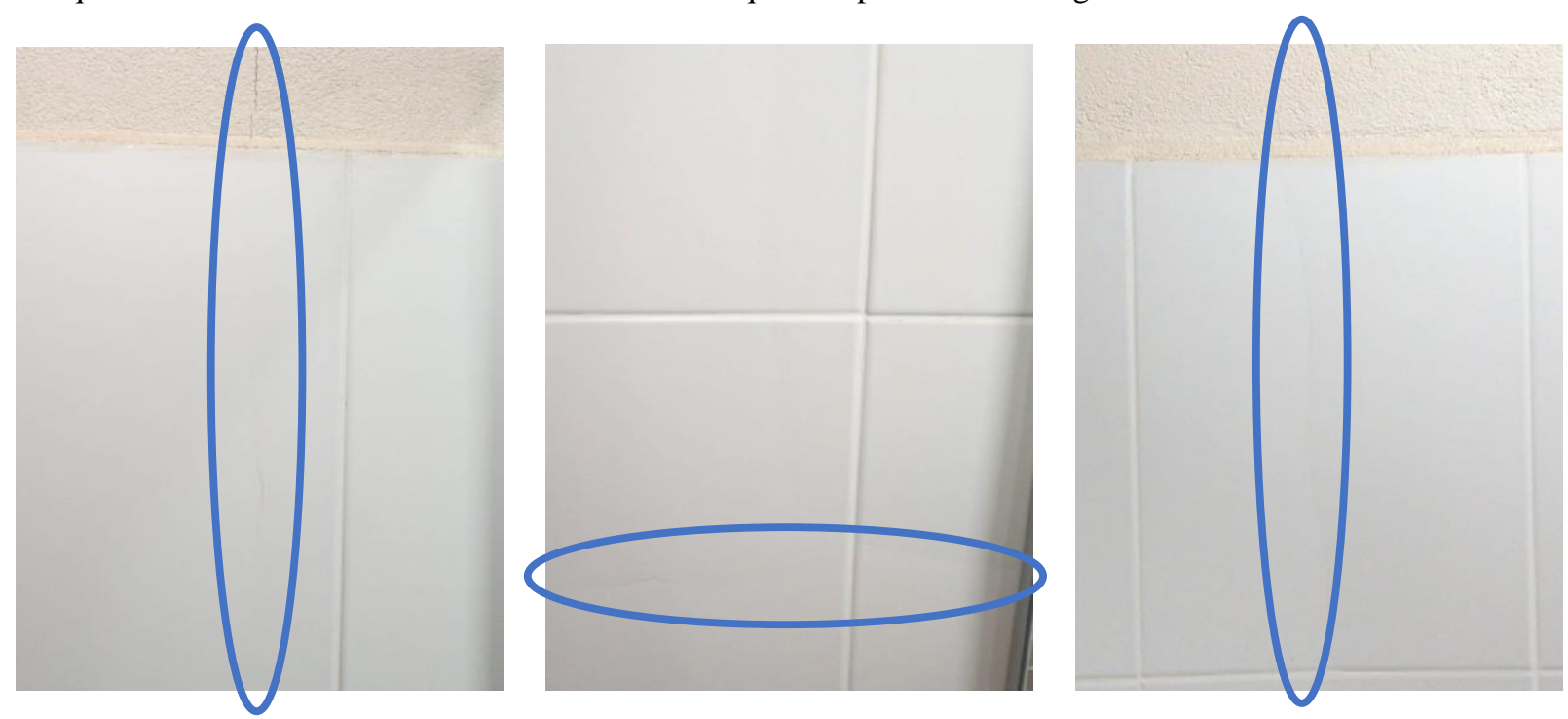

Figuras 18, 19 e 20: Descolamento da placa de fechamento da estrutura causando fissuras. (Fonte: Autores)

Esse tipo de manifestação ocorre devido às diferenças de comportamento físico dos materiais utilizados no sistema hibrido em análise (madeira x gesso x revestimento), principalmente relacionados à higroscopia e a absorção de deformações.

Outro motivo que deve ser investigado durante a análise do problema é se não se trata de fissura ativa em função de movimentação dos elementos estruturais que suportam os montantes da estrutura de fechamento (steel frame e placas). 
As vigas do pavimento são executadas em madeira roliça que funcionam como elementos de apoio para as estruturas de vedação e fechamento (steel frame e placas). Se estas vigas de madeira roliças sofrem de deslocamento ao longo do seu vão de apoio, os elementos sobre elas apoiadas também se deslocam e se deformam. Sem capacidade de suportar tais deformações, os materiais fissuram e então o revestimento adjacente também pode fissurar, por estarem aderidos ao substrato (elemento de fechamento).

Deve-se, portanto, averiguar se ocorre movimentação ativa por parte da estrutura e em caso positivo, este caso deve primeiramente ser sanado. Por se tratar de problemática estrutural, não é abordado neste trabalho esta condição. Em se tratando de fissuras que ocorreram pela movimentação que já se encontra estabilizada e não mais ocorre, ou então da deficiente ligação entre uniões verticais e horizontais das placas de fechamento (emendas), deve-se realizar a retirada do revestimento em toda a área fissurada, tratar as emendas de ligação das placas de forma adequada utilizando fitas próprias para tratamento de juntas e então realizar novamente o revestimento aderido sobre as placas de fechamento.

Especial atenção deve ser dada também nas regiões de juntas entre a estrutura de fechamento (steel frame) e a estrutura da edificação (madeira roliça), para que sejam também devidamente tratadas por meio de aplicação de PU selante flexível que apresenta ótimo desempenho nas interfaces pilar-perfil metálico-placas, conforme já mencionado.

\section{CONCLUSÃO}

A partir do levantamento de duas edificações, executadas há um tempo médio de 4 à 7 anos, registradas fotograficamente durante acompanhamento de execução das obras em questão, foi possível concluir que para análise das causas das manifestações patológicas em si (uma vez que são intrínsecas do novo sistema construtivo híbrido estudado), é necessário um estudo aprofundado sobre o tipo de fundação adotado em cada edificação, em um número maior de edificações para correlacionar ou não com as patologias encontradas, bem como classificá-las. Não foi considerado questões climatológicas, pois as duas obras analisadas foram executadas na mesma cidade, portanto, sofrendo as mesmas variações de temperatura e clima.

Nota-se que há muito campo de estudo para análise das construções que utilizam madeira em sua estrutura sejam elas pilar-viga ou outros sistemas construtivos associados ao steel frame e que há falta de material de consulta para o profissional da área.

De acordo com as manifestações patológicas conhecidas neste trabalho, não há dados suficientes para comparar edificações térreas com a de múltiplos pavimentos. Sugere-se que sejam feitos levantamento de edificações com as mesmas tipologias, com sistemas construtivos híbridos com outros diversos materiais de vedações em diferentes regiões do país para que se comparem entre eles, quais são mais indicados em função da região onde foi inserido, por conta do clima e a influência do mesmo sobre a ação destes materiais bem como o efeito de cargas diferenciadas sobre a mesma. Considera-se imprescindível um item contendo comentários conclusivos, destacando-se os principais produtos da pesquisa e suas contribuições para o conhecimento existente visando elaborar um manual de manutenção preventiva e corretiva para as edificações em questão.

\section{AGRADECIMENTOS}

Agradecemos a Professora Doutora Gisleiva Cristina dos Santos Ferreira, Professor Doutor Nilson Tadeu Mascia e as instituições de ensino UNICAMP e UNIANCHIETA por colaborarem na confecção deste trabalho.

\section{REFERÊNCIAS}

ANTUNES, G. R.; Estudo de Manifestações em Revestimentos de Fachada em Brasília -Sistematização da Incidência de Casos. 2010. Dissertação de Mestrado - Universidade de Brasília. Faculdade de Tecnologia. Brasília - DF. 178p.

ASSOCIAÇÃO BRASILEIRA DE NORMAS TÉCNICAS. NBR 15575-1 - Edifícios habitacionais de até cinco pavimentos - Desempenho - Parte 1: Requisitos gerais. Rio de Janeiro - RJ, 2013.

BARROS, M. M. S. B.; SABBATINI, F. H. Produção de revestimentos cerâmicos para paredes de vedação em alvenaria: diretrizes básicas. São Paulo: EPUSP, 2001. 
CAMPOS, H. C. Avaliação pós-ocupação de edificações construídas no sistema Light Steel Framing. 2010. Dissertação (Mestrado). Universidade Federal de Ouro Preto.

CIOCCHI, L. Use corretamente o gesso acartonado. Revista Téchne. P. 42-45. 2003.

CASTRO, R. C. M; FREITAS, A. M. S. Steel Framing: Arquitetura. CBCA, 2006.

GAIÃO, C.; BRITO, J.; SILVESTRE, J. 2011. "Inspection and diagnosis of gypsum plasterboard walls.” Journal of Performance of Constructed Facilities, Volume 25, pp. 172-180.

GROFF, Cristine. Revestimentos em fachadas: Análise das manifestações patológicas nos empreendimentos de construtora em Porto Alegre. 2011. Escola de Engenharia UFRS.

PENNA, F. C. F. Sistema light steel framing na execução de habitações de interesse social: uma abordagem pragmática. 2009. Dissertação (Mestrado). Universidade Federal de Minas Gerais.

SANTOS, P. et al. Thermal transmittance of lightweight steel framed walls: Experimental versus numerical and analytical approaches. Journal Of Building Engineering. Coimbra, set. 2019.

SILVA, A. F. Manifestações patológicas em fachadas com revestimentos de argamassa. Estudo de caso em edifício em Florianópolis, 2007. Dissertação (Mestrado em Arquitetura e Urbanismo) - Centro Tecnológico em Arquitetura e Urbanismo, UFSC, Santa Catarina, 2007.

SILVA, A. S. R.; Patologias nos sistemas de revestimentos de fachadas. 2009. VII Semana pensando em argamassa. 39 p. Salvador - BA.

SOUZA, V. C.; RIPPER, T. Patologia, recuperação e reforço de estruturas de concreto. São Paulo: Pini, 1998. 255 p. 